TRANSACTIONS OF THE

AMERICAN MATHEMATICAL SOCIETY

Volume 350, Number 7, July 1998, Pages 2973-2980

S $0002-9947(98) 02104-7$

\title{
PAIRS OF MONOTONE OPERATORS
}

\author{
S. SIMONS
}

\begin{abstract}
This note is an addendum to Sum theorems for monotone operators and convex functions. In it, we prove some new results on convex functions and monotone operators, and use them to show that several of the constraint qualifications considered in the preceding paper are, in fact, equivalent.
\end{abstract}

\section{INTRODUCTION}

We continue with the notation and the numbering of [4]. For the moment, we shall assume that $E$ is reflexive; if we not making this assumption, we shall say specifically that $E$ is a general Banach space.

Let $S_{1}, S_{2}: E \rightarrow 2^{E^{*}}$ be maximal monotone. The main result of this note is the "Six Set Theorem", Theorem 44(c), in which we prove that $\operatorname{int}\left(D\left(S_{1}\right)-D\left(S_{2}\right)\right)$ is identical with five other sets. We deduce from this in Theorem 44(d) and Theorem $44(\mathrm{e})$ that $\operatorname{int}\left(D\left(S_{1}\right)-D\left(S_{2}\right)\right)$ is always convex, and that any point surrounded by $\operatorname{co}\left(D\left(S_{1}\right)-D\left(S_{2}\right)\right)$ is always an interior point of $D\left(S_{1}\right)-D\left(S_{2}\right)$. (See Definition 38 for the technical meaning of "surrounded". It is easily seen that $\operatorname{co}\left(D\left(S_{1}\right)-D\left(S_{2}\right)\right)$ $=\operatorname{co} D\left(S_{1}\right)-\operatorname{co} D\left(S_{2}\right)$.)

We next deduce the "Nine Set Theorem", Theorem 45(a), from the Six Set Theorem. In the Nine Set Theorem, we prove the identity of $\overline{D\left(S_{1}\right)-D\left(S_{2}\right)}$ with eight other sets if $D\left(S_{1}\right)-D\left(S_{2}\right)$ is sufficiently fat. We deduce from this that $\overline{D\left(S_{1}\right)-D\left(S_{2}\right)}$ is then also convex. These results parallel results known for a single maximal monotone operator in a general Banach space. In Remark 46, we give comparisons of these two series of results.

The following eight "constraint qualifications" discussed in [4] are known to guarantee the maximal monotonicity of $S_{1}+S_{2}$ :

$$
\begin{gathered}
D\left(S_{1}\right)-D\left(S_{2}\right) \quad \text { is absorbing, } \\
\operatorname{co} D\left(S_{1}\right)-\operatorname{co} D\left(S_{2}\right) \quad \text { is absorbing, } \\
\operatorname{dom} \chi_{S_{1}}-\operatorname{dom} \chi_{S_{2}} \quad \text { is absorbing, } \\
\bigcup_{\lambda>0} \lambda\left(D\left(S_{1}\right)-D\left(S_{2}\right)\right)=\varlimsup \\
\operatorname{lin}\left(D\left(S_{1}\right)-D\left(S_{2}\right)\right), \\
\operatorname{co} D\left(S_{1}\right)-\operatorname{co} D\left(S_{2}\right) \quad \text { is a neighborhood of } 0 \text { in }
\end{gathered}
$$

Received by the editors December 10, 1996.

1991 Mathematics Subject Classification. Primary 47H05; Secondary $46 B 10$.

Key words and phrases. Banach space, reflexivity, maximal monotone operator, sum theorem, constraint qualification, proper convex lower semicontinuous function.

(C)1998 American Mathematical Society 


$$
\begin{gathered}
\bigcup_{\lambda>0} \lambda\left[\operatorname{co} D\left(S_{1}\right)-\operatorname{co} D\left(S_{2}\right)\right]=\overline{\operatorname{lin}\left(D\left(S_{1}\right)-D\left(S_{2}\right)\right)}, \\
\bigcup_{\lambda>0} \lambda\left[\operatorname{dom} \chi_{S_{1}}-\operatorname{dom} \chi_{S_{2}}\right]=\overline{\operatorname{lin}\left(\operatorname{dom} \chi_{S_{1}}-\operatorname{dom} \chi_{S_{2}}\right)},
\end{gathered}
$$

and

$$
S_{1} \text { and } S_{2} \text { satisfy the " } \chi \text { constraint condition" }
$$

(see Definition 48). Furthermore, (0.4) is formally weaker than (0.2) and (0.3), and (37.1) is formally weaker than $(0.5),(0.6),(0.7)$ and $(23.1)$. We shall show in Theorem 47 that $(0.2),(0.3)$ and $(0.4)$ are, in fact, equivalent. This equivalence is not trivial, relying as it does on Theorem 44(a), which relies on Lemma 43, which relies in turn on Lemma 17, the crucial step in the proof of Corollary 20. We shall show in Theorem 49 that $(0.5),(0.6),(0.7),(23.1)$ and (37.1) are also equivalent. Theorem 49 uses not only Theorem 47 , but also a new result on the function $\chi_{T}$ (see Lemma 41(b)).

The technique introduced in this note is an application to operators of the technique applied to functions in Theorem 36.

Most of the results in the initial section on preliminaries are taken from [4]. Lemma 41(b), which we have already mentioned, is an exception. We bootstrap this result in Theorem 42 and obtain the new result that - even in a general Banach space - if $S$ is maximal monotone then $\operatorname{dom} \chi_{S}$ and $D(S)$ have the same closed affine hull.

\section{PRELIMINARIES}

We point out for the record that Lemma 39, Lemma 40, Lemma 41 and Theorem 42 are all valid in a general Banach space. Reflexivity is used in our proof of Lemma 43 (see Lemma 17). In this note, we only need the weaker conclusion "there exists $z \in D\left(S_{1}+S_{2}\right)$ ". It is conceivable that this is true in a general Banach space, without the assumption of reflexivity.

Definition 38. (See Remark 12.) Let $E$ be a general Banach space, $x \in E$ and $A \subset E$. We write " $x \in \operatorname{sur} A$ " and say that " $A$ surrounds $x$ " if, for each $w \in E \backslash\{0\}$, there exists $\delta>0$ such that $x+\delta w \in A$. The statement " $x \in \operatorname{sur} A$ " is related to $x$ being an "absorbing point" of $A$ (see [3], Definition 2.27(b), p. 28), but differs in that we do not require that $x \in A$. We also note that

$$
\text { if } A \text { is convex then } \quad(0 \in \operatorname{sur} A \Longleftrightarrow A \text { is absorbing }) \text {. }
$$

Lemma 39. Let $E$ be a general Banach space, and let $g_{1}, g_{2}: E \rightarrow \mathbb{R} \cup\{\infty\}$ be convex, lower semicontinuous functions. Then

$$
\operatorname{sur}\left(\operatorname{dom} g_{1}-\operatorname{dom} g_{2}\right)=\operatorname{int}\left(\operatorname{dom} g_{1}-\operatorname{dom} g_{2}\right) .
$$

Proof. We shall prove that

$$
\operatorname{sur}\left(\operatorname{dom} g_{1}-\operatorname{dom} g_{2}\right) \subset \operatorname{int}\left(\operatorname{dom} g_{1}-\operatorname{dom} g_{2}\right) .
$$

This gives the desired result, since the reverse inclusion is trivial. So let

$$
x \in \operatorname{sur}\left(\operatorname{dom} g_{1}-\operatorname{dom} g_{2}\right) .
$$


Define $g_{3}: E \rightarrow \mathbb{R} \cup\{\infty\}$ by $g_{3}(y):=g_{1}(y+x) \quad(y \in E)$. Then $\operatorname{dom} g_{3}=$ $\operatorname{dom} g_{1}-x$, from which it follows that

$$
0 \in \operatorname{sur}\left(\operatorname{dom} g_{3}-\operatorname{dom} g_{2}\right) .
$$

From (38.1), $\operatorname{dom} g_{3}-\operatorname{dom} g_{2}$ is absorbing; hence, from Corollary 4 ,

$$
0 \in \operatorname{int}\left(\operatorname{dom} g_{3}-\operatorname{dom} g_{2}\right)=\operatorname{int}\left(\operatorname{dom} g_{1}-x-\operatorname{dom} g_{2}\right) .
$$

Thus $x \in \operatorname{int}\left(\operatorname{dom} g_{1}-\operatorname{dom} g_{2}\right)$, which completes the proof of (39.1).

Lemma 40. Let $E$ be a general Banach space, $T: E \rightarrow 2^{E^{*}}$ a monotone operator and $D(T) \neq \emptyset$. Let $w \in E$ and $S=\left(T^{-1}-w\right)^{-1}$. Then $D(S)=D(T)-w$.

Proof. This is immediate since $S x=T(x+w) \quad(x \in E)$.

Lemma 41 is a continuation of Lemma 25.

Lemma 41. Let $E$ be a general Banach space, $F$ a closed subspace of $E, T: E \rightarrow$ $2^{E^{*}}$ a monotone operator and $D(T) \subset F$. Define $\left.T\right|_{F}: F \rightarrow 2^{F^{*}}$ by

$$
\left(\left.T\right|_{F}\right) x:=\left\{\left.x^{*}\right|_{F}: x^{*} \in T x\right\} .
$$

Then:

(a) $D\left(\left.T\right|_{F}\right)=D(T)$.

(b) If $T$ is maximal monotone then $\operatorname{dom} \chi_{T} \subset F$.

(c) If $T$ is maximal monotone then $\operatorname{dom} \chi_{\left(\left.T\right|_{F}\right)}=\operatorname{dom} \chi_{T}$.

Proof. We leave to the reader the proof of (a), which is fairly straightforward.

(b) Let $x \in \operatorname{dom} \chi_{T}$ and $t \in D(T)$. Fix $t^{*} \in T t$. We first prove that

$$
y^{*} \in E^{*} \text { and }\left.y^{*}\right|_{F}=0 \quad \Longrightarrow \quad\left\langle x-t, y^{*}\right\rangle=0 .
$$

Let $y^{*} \in E^{*}$ and $\left.y^{*}\right|_{F}=0$. Let $\lambda$ be an arbitrary real number. From Lemma 25(c), $T$ is $F$-saturated (see Definition 24) and so $\left(t, t^{*}+\lambda y^{*}\right) \in G(T)$. Thus, from the definition of $\chi_{T}(x)$,

$$
\frac{\left\langle x, t^{*}+\lambda y^{*}\right\rangle-\left\langle t, t^{*}+\lambda y^{*}\right\rangle}{1+\|t\|} \leq \chi_{T}(x) ;
$$

hence

$$
\lambda\left\langle x-t, y^{*}\right\rangle \leq(1+\|t\|) \chi_{T}(x)-\left\langle x-t, t^{*}\right\rangle .
$$

Since this holds for all $\lambda \in \mathbb{R},\left\langle x-t, y^{*}\right\rangle=0$, which completes the proof of (41.1). Now $F$ is closed, so it follows from (41.1) and the separation theorem that $x-t \in F$. Since $t \in D(T) \subset F, x=t+(x-t) \in F$. This completes the proof of (b).

(c) is immediate from (b) and Lemma 25(b).

Theorem 42. Let $E$ be a general Banach space and $S: E \rightarrow 2^{E^{*}}$ a maximal monotone operator. Then

$$
\overline{\operatorname{aff}\left(\operatorname{dom} \chi_{S}\right)}=\overline{\operatorname{aff} D(S)},
$$

where "aff" stands for "affine hull of". 
Proof. We shall prove that

$$
\overline{\operatorname{aff}\left(\operatorname{dom} \chi_{S}\right)} \subset \overline{\operatorname{aff} D(S)} .
$$

This gives the desired result, since the reverse inclusion is immediate from Lemma 9. Let $x \in D(S)$ and $T=\left(S^{-1}-x\right)^{-1}$. $T$ is easily seen to be maximal monotone. From Lemma 40,

$$
D(T)=D(S)-x
$$

and, from Lemma 10,

$$
\operatorname{dom} \chi_{S}=\operatorname{dom} \chi_{T}+x .
$$

It follows from $(42.2)$ that $D(T) \ni 0$, and $\operatorname{so} \operatorname{lin} D(T)=\operatorname{aff} D(T)$. Substituting this back in (42.2), we obtain

$$
\operatorname{lin} D(T)=\operatorname{aff}(D(S)-x)=\operatorname{aff} D(S)-x .
$$

From Lemma 41(b) with $F:=\overline{\operatorname{lin} D(T)}, \operatorname{dom} \chi_{T} \subset \overline{\operatorname{lin} D(T)}$. Combining this with (42.4), we see that $\operatorname{dom} \chi_{T} \subset \overline{\operatorname{aff} D(S)-x}=\overline{\operatorname{aff} D(S)}-x$. Thus, using (42.3),

$$
\operatorname{dom} \chi_{S} \subset \overline{\operatorname{aff} D(S)}
$$

from which (42.1) follows immediately.

Lemma 43. Let $E$ be a reflexive Banach space, let $S_{1}, S_{2}: E \rightarrow 2^{E^{*}}$ be maximal monotone operators, and let $\operatorname{dom} \chi_{S_{1}}-\operatorname{dom} \chi_{S_{2}}$ be absorbing. Then there exists $\left(z, z^{*}\right) \in G\left(S_{1}+S_{2}\right)$ such that

$$
\|z\|^{2}+\left\|z^{*}\right\|^{2}+2\left\langle z, z^{*}\right\rangle=0
$$

Proof. See Lemma 17.

\section{The Six Set Theorem and the Nine Set Theorem}

Our next result, Theorem 44, is the main result of this note.

Theorem 44. Let $E$ be a reflexive Banach space and $S_{1}, S_{2}: E \rightarrow 2^{E^{*}}$ be maximal monotone operators. Then:

(a) $\operatorname{Sur}\left(\operatorname{dom} \chi_{S_{1}}-\operatorname{dom} \chi_{S_{2}}\right) \subset D\left(S_{1}\right)-D\left(S_{2}\right)$.

(b) $\operatorname{Sur}\left(\operatorname{dom} \chi_{S_{1}}-\operatorname{dom} \chi_{S_{2}}\right) \subset \operatorname{int}\left(D\left(S_{1}\right)-D\left(S_{2}\right)\right)$.

(c) $\operatorname{Int}\left(D\left(S_{1}\right)-D\left(S_{2}\right)\right)=\operatorname{int}\left(\operatorname{co} D\left(S_{1}\right)-\operatorname{co} D\left(S_{2}\right)\right)=\operatorname{int}\left(\operatorname{dom} \chi_{S_{1}}-\operatorname{dom} \chi_{S_{2}}\right)=$ $\operatorname{sur}\left(D\left(S_{1}\right)-D\left(S_{2}\right)\right)=\operatorname{sur}\left(\operatorname{co} D\left(S_{1}\right)-\operatorname{co} D\left(S_{2}\right)\right)=\operatorname{sur}\left(\operatorname{dom} \chi_{S_{1}}-\operatorname{dom} \chi_{S_{2}}\right)$.

(d) $\operatorname{Int}\left(D\left(S_{1}\right)-D\left(S_{2}\right)\right)$ is convex.

(e) $\operatorname{Sur}\left(\operatorname{co} D\left(S_{1}\right)-\operatorname{co} D\left(S_{2}\right)\right) \subset \operatorname{int}\left(D\left(S_{1}\right)-D\left(S_{2}\right)\right)$.

Proof. Let $x \in \operatorname{sur}\left(\operatorname{dom} \chi_{S_{1}}-\operatorname{dom} \chi_{S_{2}}\right)$. Define $S_{3}: E \rightarrow 2^{E^{*}}$ by $S_{3}:=\left(S_{1}^{-1}-x\right)^{-1}$. From Lemma 40 and Lemma 10,

$$
D\left(S_{3}\right)=D\left(S_{1}\right)-x \text { and } \operatorname{dom} \chi_{S_{3}}=\operatorname{dom} \chi_{S_{1}}-x ;
$$

thus, by hypothesis,

$$
0 \in \operatorname{sur}\left(\operatorname{dom} \chi_{S_{1}}-x-\operatorname{dom} \chi_{S_{2}}\right)=\operatorname{sur}\left(\operatorname{dom} \chi_{S_{3}}-\operatorname{dom} \chi_{S_{2}}\right) .
$$

From (38.1), dom $\chi_{S_{3}}-\operatorname{dom} \chi_{S_{2}}$ is absorbing; hence, from Lemma 43, there exists

$$
z \in D\left(S_{3}+S_{2}\right)=D\left(S_{3}\right) \cap D\left(S_{2}\right) .
$$


From (44.1), there exists $y \in D\left(S_{1}\right)$ such that $z=y-x$. But then

$$
x=y-z \in D\left(S_{1}\right)-D\left(S_{2}\right) .
$$

This completes the proof of (a). However, it follows from Lemma 39 that

$$
\operatorname{sur}\left(\operatorname{dom} \chi_{S_{1}}-\operatorname{dom} \chi_{S_{2}}\right) \text { is open; }
$$

thus (b) is a consequence of (a). From Lemma 9,

$$
\operatorname{int}\left(D\left(S_{1}\right)-D\left(S_{2}\right)\right) \subset \operatorname{int}\left(\operatorname{co} D\left(S_{1}\right)-\operatorname{co} D\left(S_{2}\right)\right) \subset \operatorname{int}\left(\operatorname{dom} \chi_{S_{1}}-\operatorname{dom} \chi_{S_{2}}\right)
$$

and

$$
\operatorname{sur}\left(D\left(S_{1}\right)-D\left(S_{2}\right)\right) \subset \operatorname{sur}\left(\operatorname{co} D\left(S_{1}\right)-\operatorname{co} D\left(S_{2}\right)\right) \subset \operatorname{sur}\left(\operatorname{dom} \chi_{S_{1}}-\operatorname{dom} \chi_{S_{2}}\right) .
$$

Since $\operatorname{int}(\ldots) \subset \operatorname{sur}(\ldots)$, (c) follows from (b). Finally, (d) and (e) are immediate from $(\mathrm{c})$.

Theorem 45. Let $E$ be a reflexive Banach space, $S_{1}, S_{2}: E \rightarrow 2^{E^{*}}$ maximal monotone operators and

$$
\operatorname{sur}\left(\operatorname{dom} \chi_{S_{1}}-\operatorname{dom} \chi_{S_{2}}\right) \neq \emptyset .
$$

Then:

(a)

$$
\text { a) } \begin{aligned}
\overline{D\left(S_{1}\right)-D\left(S_{2}\right)} & =\overline{\operatorname{co} D\left(S_{1}\right)-\operatorname{co} D\left(S_{2}\right)}=\overline{\operatorname{dom} \chi_{S_{1}}-\operatorname{dom} \chi_{S_{2}}} \\
=\overline{\operatorname{int}\left(D\left(S_{1}\right)-D\left(S_{2}\right)\right)} & =\overline{\operatorname{int}\left(\operatorname{co} D\left(S_{1}\right)-\operatorname{co} D\left(S_{2}\right)\right)}=\overline{\operatorname{int}\left(\operatorname{dom} \chi_{S_{1}}-\operatorname{dom} \chi_{S_{2}}\right)} \\
=\overline{\operatorname{sur}\left(D\left(S_{1}\right)-D\left(S_{2}\right)\right)} & =\overline{\operatorname{sur}\left(\operatorname{co} D\left(S_{1}\right)-\operatorname{co} D\left(S_{2}\right)\right)}=\overline{\operatorname{sur}\left(\operatorname{dom} \chi_{S_{1}}-\operatorname{dom} \chi_{S_{2}}\right)} .
\end{aligned}
$$

(b) $\overline{D\left(S_{1}\right)-D\left(S_{2}\right)}$ is convex.

Proof. From Lemma 9,

$$
\overline{D\left(S_{1}\right)-D\left(S_{2}\right)} \subset \overline{\operatorname{co} D\left(S_{1}\right)-\operatorname{co} D\left(S_{2}\right)} \subset \overline{\operatorname{dom} \chi_{S_{1}}-\operatorname{dom} \chi_{S_{2}}} .
$$

Clearly,

$$
\overline{\operatorname{int}\left(D\left(S_{1}\right)-D\left(S_{2}\right)\right)} \subset \overline{D\left(S_{1}\right)-D\left(S_{2}\right)} .
$$

From Lemma 39, $\operatorname{int}\left(\operatorname{dom} \chi_{S_{1}}-\operatorname{dom} \chi_{S_{2}}\right) \neq \emptyset$; hence (see, for instance, [2], 13.1(i), pp. 100-111)

$$
\overline{\operatorname{dom} \chi_{S_{1}}-\operatorname{dom} \chi_{S_{2}}}=\overline{\operatorname{int}\left(\operatorname{dom} \chi_{S_{1}}-\operatorname{dom} \chi_{S_{2}}\right)} .
$$

(a) now follows from Theorem 44(c), and (b) is an immediate consequence of (a).

Remark 46 (See also Remark 12). The following results, valid for general Banach spaces, were proved in [1], Theorem 14, pp. 95-96.

Let $S: E \rightarrow 2^{E^{*}}$ be maximal monotone. Then

$$
\begin{gathered}
\operatorname{int} D(S)=\operatorname{int}(\operatorname{co} D(S))=\operatorname{int}\left(\operatorname{dom} \chi_{S}\right) \\
=\operatorname{sur} D(S)=\operatorname{sur}(\operatorname{co} D(S))=\operatorname{sur}\left(\operatorname{dom} \chi_{S}\right) .
\end{gathered}
$$

Let $S: E \rightarrow 2^{E^{*}}$ be maximal monotone and $\operatorname{sur}\left(\operatorname{dom} \chi_{S}\right) \neq \emptyset$. Then

$$
\begin{gathered}
\overline{D(S)}=\overline{\operatorname{co} D(S)}=\overline{\operatorname{dom} \chi_{S}} \\
=\overline{\operatorname{int} D(S)}=\overline{\operatorname{int}(\operatorname{co} D(S))}=\overline{\operatorname{int}\left(\operatorname{dom} \chi_{S}\right)} \\
=\overline{\operatorname{sur} D(S)}=\overline{\operatorname{sur}(\operatorname{co} D(S))}=\overline{\operatorname{sur}\left(\operatorname{dom} \chi_{S}\right)} .
\end{gathered}
$$


Theorem 44(c) and Theorem 45(a) give analogs for pairs of maximal monotone operators for reflexive spaces. Of course, these results are much "harder" than the results proved in [1], since they use Lemma 17.

\section{CONSTRAINT QUALIFICATIONS}

In this final section, we apply Theorem $44(\mathrm{c})$ and Lemma 41 to show the equivalence of various constraint qualifications that have been used to establish the maximal monotonicity of $S_{1}+S_{2}$ in reflexive spaces.

Theorem 47. Let $E$ be a reflexive Banach space and $S_{1}, S_{2}: E \rightarrow 2^{E^{*}}$ be maximal monotone operators. Then the six conditions below are equivalent:

$$
\begin{gathered}
D\left(S_{1}\right)-D\left(S_{2}\right) \quad \text { is a neighborhood of } 0, \\
D\left(S_{1}\right)-D\left(S_{2}\right) \quad \text { is absorbing, } \\
D\left(S_{1}\right)-D\left(S_{2}\right) \quad \text { surrounds } 0, \\
\operatorname{co} D\left(S_{1}\right)-\operatorname{co} D\left(S_{2}\right) \quad \text { is absorbing, } \\
\operatorname{co} D\left(S_{1}\right)-\operatorname{co} D\left(S_{2}\right) \quad \text { is a neighborhood of } 0, \\
\operatorname{dom} \chi_{S_{1}}-\operatorname{dom} \chi_{S_{2}} \quad \text { is absorbing. }
\end{gathered}
$$

Proof. Using (38.1), the equivalence of (47.1), (47.2), (0.3), (47.3) and (0.4) follows by putting " $0 \in$ " in front of the first, fourth, fifth, second and sixth sets, respectively, of Theorem 44(c). (0.2) is intermediate between (47.1) and (47.2).

Definition 48. (See Definition 22.) Let $S_{1}, S_{2}: E \rightarrow 2^{E^{*}}$ be monotone operators. We say that $S_{1}, S_{2}$ satisfy the $\chi$ constraint qualification if there exist $w \in E$ and a closed subspace $F$ of $E$ such that

$$
D\left(S_{i}\right) \subset w+F \quad \text { for } i=1,2
$$

and

$$
\bigcup_{\lambda>0} \lambda\left[(w+F) \cap \operatorname{dom} \chi_{S_{1}}-(w+F) \cap \operatorname{dom} \chi_{S_{2}}\right]=F .
$$

Theorem 49. Let $E$ be a reflexive Banach space, and let $S_{1}, S_{2}: E \rightarrow 2^{E^{*}}$ be maximal monotone operators. Then the seven conditions below are equivalent:

$$
D\left(S_{1}\right)-D\left(S_{2}\right) \quad \text { is a neighborhood of } 0 \text { in } \overline{\operatorname{lin}\left(D\left(S_{1}\right)-D\left(S_{2}\right)\right)} \text {, }
$$

$$
\begin{gathered}
\bigcup_{\lambda>0} \lambda\left[D\left(S_{1}\right)-D\left(S_{2}\right)\right]=\varlimsup \\
\operatorname{co} D\left(S_{1}\right)-\operatorname{co} D\left(S_{2}\right) \quad \text { is a neighborhood of } 0 \text { in } \overline{\operatorname{lin}\left(D\left(S_{1}\right)-D\left(S_{2}\right)\right)}, \\
\bigcup_{\lambda>0} \lambda\left[\operatorname{co} D\left(S_{1}\right)-\operatorname{co} D\left(S_{2}\right)\right]=\overline{\operatorname{lin}\left(D\left(S_{1}\right)-D\left(S_{2}\right)\right)}
\end{gathered}
$$

(49.2) $\operatorname{dom} \chi_{S_{1}}-\operatorname{dom} \chi_{S_{2}} \quad$ is a neighborhood of 0 in $\overline{\operatorname{lin}\left(\operatorname{dom} \chi_{S_{1}}-\operatorname{dom} \chi_{S_{2}}\right)}$, 


$$
\bigcup_{\lambda>0} \lambda\left[\operatorname{dom} \chi_{S_{1}}-\operatorname{dom} \chi_{S_{2}}\right]=\varlimsup
$$

$S_{1}$ and $S_{2}$ satisfy the $\chi$ constraint condition.

Proof. Clearly (49.1) $\Longrightarrow(0.5) \Longrightarrow(0.7)$, and (49.1) $\Longrightarrow(0.6) \Longrightarrow(0.7)$; and it was proved in Lemma 23 that $(0.7) \Longrightarrow(37.1)$. Further, $(49.2) \Longrightarrow(23.1)$. Thus it remains to prove that $(23.1) \Longrightarrow(37.1),(37.1) \Longrightarrow(49.1)$ and $(37.1) \Longrightarrow(49.2)$.

$((23.1) \Longrightarrow(37.1))$ Let $F:=\overline{\operatorname{lin}\left(\operatorname{dom} \chi_{S_{1}}-\operatorname{dom} \chi_{S_{2}}\right)}$. Since $0 \in F$, it follows from (23.1) that $0 \in \operatorname{dom} \chi_{S_{1}}-\operatorname{dom} \chi_{S_{2}}$; hence there exists $w \in \operatorname{dom} \chi_{S_{1}} \cap \operatorname{dom} \chi_{S_{2}}$. From Lemma 9,

$$
D\left(S_{1}\right)-w \subset \operatorname{dom} \chi_{S_{1}}-w \subset \operatorname{dom} \chi_{S_{1}}-\operatorname{dom} \chi_{S_{2}} \subset F
$$

and

$$
D\left(S_{2}\right)-w \subset \operatorname{dom} \chi_{S_{2}}-w \subset \operatorname{dom} \chi_{S_{2}}-\operatorname{dom} \chi_{S_{1}} \subset F .
$$

These two sets of inclusions give (48.1), and also imply that,

$$
\text { for } i=1,2, \quad \operatorname{dom} \chi_{S_{i}}=(w+F) \cap \operatorname{dom} \chi_{S_{i}} .
$$

Consequently, (23.1) gives (48.2). This establishes (37.1).

Now suppose that $S_{1}$ and $S_{2}$ satisfy the $\chi$ constraint condition. Let $w$ and $F$ be as in Definition 48, and $T_{i}:=\left(S_{i}^{-1}-w\right)^{-1}$. Clearly, $T_{1}$ and $T_{2}$ are maximal monotone. Using Lemma 40 and Lemma 10 on (48.1) and (48.2), we get

$$
\text { for } i=1,2, \quad D\left(T_{i}\right) \subset F
$$

and

$$
\bigcup_{\lambda>0} \lambda\left[F \cap \operatorname{dom} \chi_{T_{1}}-F \cap \operatorname{dom} \chi_{T_{2}}\right]=F .
$$

Combining this with Lemma 25(b),

$$
\bigcup_{\lambda>0} \lambda\left[\operatorname{dom} \chi_{\left(\left.T_{1}\right|_{F}\right)}-\operatorname{dom} \chi_{\left(\left.T_{2}\right|_{F}\right)}\right]=F .
$$

From Lemma 25(c), $\left.T_{1}\right|_{F}$ and $\left.T_{2}\right|_{F}$ are maximal monotone; hence, from Theorem 47 ,

$$
D\left(\left.T_{1}\right|_{F}\right)-D\left(\left.T_{2}\right|_{F}\right) \text { is a neighborhood of } 0 \text { in } F .
$$

Now, from Lemma 40 and Lemma 41(a),

$$
D\left(S_{1}\right)-D\left(S_{2}\right)=D\left(T_{1}\right)-D\left(T_{2}\right)=D\left(\left.T_{1}\right|_{F}\right)-D\left(\left.T_{2}\right|_{F}\right) ;
$$

hence

$$
D\left(S_{1}\right)-D\left(S_{2}\right) \quad \text { is a neighborhood of } 0 \text { in } F .
$$

It also follows from (49.3) and Lemma 41(b) that $\operatorname{dom} \chi_{T_{i}} \subset F \quad(i=1,2)$; hence, since $F$ is a subspace, $\operatorname{dom} \chi_{T_{1}}-\operatorname{dom} \chi_{T_{2}} \subset F$. Using Lemma 10, dom $\chi_{S_{1}}-$ $\operatorname{dom} \chi_{S_{2}} \subset F$. From Lemma 9 and (49.4),

$$
\operatorname{dom} \chi_{S_{1}}-\operatorname{dom} \chi_{S_{2}} \text { is a neighborhood of } 0 \text { in } F \text {. }
$$

Since $F$ is a closed subspace, from (49.4) and (49.5),

$$
\overline{\operatorname{lin}\left(D\left(S_{1}\right)-D\left(S_{2}\right)\right)} \subset F \quad \text { and } \overline{\operatorname{lin}\left(\operatorname{dom} \chi_{S_{1}}-\operatorname{dom} \chi_{S_{2}}\right)} \subset F .
$$

It now follows from (49.4), (49.5) and (49.6) that (49.1) and (49.2) hold. This completes the proof that (37.1) $\Longrightarrow(49.1)$ and $(37.1) \Longrightarrow(49.2)$. 


\section{REFERENCES}

1. M. Coodey and S. Simons, The convex function determined by a multifunction, Bull. Austral. Math. Soc. 54 (1996), 87-97. CMP 96:16

2. J. L. Kelley, I. Namioka et al., Linear Topological Spaces, Van Nostrand, Princeton, 1963. MR 29:3851

3. R. R. Phelps, Convex Functions, Monotone Operators and Differentiability, Lecture Notes in Mathematics 1364 (Second Edition), Springer-Verlag, Berlin, 1993. MR 94f: 46055

4. S. Simons, Sum theorems for monotone operators and convex functions, Trans. Amer. Math. Soc., 350 (1998), 2953-2972.

Department of Mathematics, University of California, Santa Barbara, California 93106-3080

E-mail address: simons@math.ucsb.edu 